\title{
The sequence of manipulation matters: Abstract thinking offsets ego-depletion when induced before, but not after a depleting task
}

\author{
Alexander Unger ${ }^{1}$. Julie Papastamatelou ${ }^{1}$
}

Accepted: 6 December 2021

(c) The Author(s) 2021

\begin{abstract}
Based on theoretical and empirical studies dealing with the facilitation and inhibiting effects of different psychic distances (low vs. high construal-level), we tested if the exhibition of self-control under a high construal-level is a more efficient and less resource exhausting mode, compared to the exhibition of self-control under a low construal level. Prior studies already showed that the execution of self-control results in a lower construal-level and a high construal-level has facilitating effects on self-control. We expand upon these studies by: 1. operationalizing the whole process of ego-depletion through two sequential self-control tasks, 2. combining one ego-depletion and one construal-level manipulation in a 2 by 2 design and 3. varying the sequence of manipulations. In Experiment 1, we examined how the manipulation of the participants before and after being depleted, affects the self-control performance in a final task. In Experiment 2, we re-tested the offset of ego-depletion on another self-control measurement, with the condition of a high construal-level manipulated first. In Experiment 1 the ego-depletion effect remained existent when the construal-level was manipulated after the execution of self-control in a stroop test, but it was offset, when the construal-level was manipulated before the stoop test. Drawing on measurements of the perceived available self-control resources in Experiment 2, we were able to rule out an alternative approach, explaining similar results by an attentional shift towards reduced resources under low construal-level.
\end{abstract}

\section{Introduction}

The core idea of the construal-level theory (Liberman et al., 2002; Liberman \& Trope, 2008; Trope \& Liberman, 2010) consists of a continuum from a very concrete to a very abstract mode of thinking (often also referred to as concrete versus abstract mind-set). Several studies have revealed that the degree of abstraction has essential consequences for human behavior, including financial decisions (Ülkümen \& Cheema, 2011), preferences for short-term versus long-term goals (Trope \& Liberman, 2000), altered subjective time perception (Hansen \& Trope, 2013), different task duration estimates for difficult and easy tasks (Siddiqui et al., 2014), preferred type of self-evaluation (Freitas et al., 2001), motivational goal orientation (Liberman \& Trope, 1998) and

Alexander Unger

alunger@web.de

Julie Papastamatelou

JPapas@gmx.net

1 Ludwigshafen University of Business and Society (Former Name: University of Applied Sciences Ludwigshafen, Ernst-Böhe Str. 4, 67059 Ludwigshafen, Germany self-control (Fujita, Henderson, et al., 2006; Fujita, Trope, et al., 2006).

Trope and Liberman (2010) suggested four dimensions of psychological distance, namely time, space, social distance and probability. The first dimension of time can be illustrated by an event that will either take place tomorrow or in five years. Second, the dimension of space can be characterized by traveling to a neighborhood city versus to an overseas destination. The third dimension of social distance refers to a continuum of intimate to more formal social relationships, which can be exemplified by either talking with a close friend versus talking with the CEO of a company. Finally the dimension of probability encompass a continuum of very probable to very improbable events, like the example of a Japanese traveling to Yamagata, to New York or to the moon ranging from very probable to very improbable.

These different dimensions were assumed to be interchangeable and related to each other (Fujita, Henderson, et al., 2006; Fujita, Trope, et al., 2006; Nan, 2007; Stephan et al., 2011; Wakslak, \& Trope, 2009). The common basis and relatedness of all four dimensions was demonstrated by the findings of Fiedler et al. (2012). In addition, various studies indicated that language concreteness (Hansen \& 
Wänke, 2010) and politeness express psychological distance, which is loosely related to the social distance dimension (Stephan et al., 2010).

The replicability of the construal-level theory was questioned in the context of the replication crisis of psychology: There were some contradictory results, which concern some specific aspects like the influence on moral judgments (Žeželj \& Jokić, 2014) or the subjective likelihood as one of the dimensions of psychic abstraction (Calderon et al., 2020). Overall however it can be summarized that the effects seemed to be robust and a meta-analysis including 106 articles with 267 experiments confirmed (Soderberg et al., 2015) important core assumptions of the construal-level theory. These authors reported a "reliable and medium-sized effect [...] across time, researchers, and settings." (p. 525) A preregistered international multilab replication study of a broader testing of the construal-level theory is still outstanding but is scheduled by the European Association of Social Psychology (EASP, 2021) for 2021.

Several studies reported that abstract mind-sets facilitate some kind of self-control, including enhanced self-control by changed implicit non-deliberative evaluations of temptations (Fujita \& Han, 2009), altered temptation-goal associations (Fujita \& Sasota, 2011) and enhanced foresightedness (Fujita \& Roberts, 2010).

Other research has concentrated on the reversed influence, by testing how the execution of self-control alters the degree of abstract thinking: Bruyneel and Dewitte (2012) reported low construal-level following the execution of selfcontrol. In three experiments, they were able to demonstrate that the execution of self-control leads to a low construallevel. Thus, most available studies investigated only one way of influence, either the enhancing effect of abstract thinking on self-control (Fujita \& Carnevale, 2012; Fujita \& Han, 2009; Fujita \& Roberts, 2010; Fujita, Henderson, et al., 2006; Fujita, Trope, et al., 2006) or a low construal-level following the execution of self-control (Bruyneel \& Dewitte, 2006, 2012; Bruyneel et al., 2005).

The findings on construal-level changing self-control performance, led to the idea that the execution of selfcontrol under high and low construal-level might differ in substantial ways. This implies the parsimonious exhaustion of self-control resources with maintained self-control performance. A high construal-level enables individuals to be less focused on the concrete requirements of the task. Alberts et al. (2008, p. 331) argued " [...] that self-control performance would increase when one focused attention away from the unpleasant, resistance-related sensations generated by the self-control task." This kind of abstract mode enables better self-control performance. Therefore, less resources are exhausted for the completion of the same task, compared to conditions under a low construal-level. Previous explanations imply that individuals thinking in an abstract mode, had a reduced focus on their available selfcontrol resources. Following this explanation, individuals under a high construal-level did not recognize their exhausted resources of self-control (Agrawal \& Wan, 2009; Wan \& Agrawal, 2011).

In line with Fujita (2008), several studies have shown that automatization can facilitate self-control by saving selfcontrol resources. Thus, there is support for the assumption that automatized if-then rules can be helpful to overcome ego-depletion and to enhance self-control respectively (Gollwitzer, 1999; Gollwitzer \& Sheeran, 2006; Webb \& Sheeran, 2003). Evidence for the importance of implicit, indirect and more automatized processes of self-control is widespread in the literature as in example in the context of goal activation (Bargh et al., 2001). Automatic processes dealing with a task can be assumed to be enhanced when the construal-level is high, whereas a low construal-level implies more deliberative and thus effortful processing of self-control tasks.

Self-control can be more easily automatized when led by higher-ranked goals as suggested by Fujita (2008), when individuals operate on a high construal-level. These goals are not directly connected to the task at stake and they are of general character, such as the goal of performing well. The preference for high construal decisions could be mainly explained by the current functioning of individual mindsets facilitating the accessibility of long-term goals and not by the perception of decreased mental resources. Enhanced readiness to act in line with the current mind-set or motives to adapt current decisional behavior to the prevailing mindset are further explanations.

The separate influence of self-control on construal-level and vice versa has been quite good documented as the enhancing effect of a high construal-level on self-control or a lowered construal-level following the execution of selfcontrol. However, studies, which examine the manipulations of ego-depletion and construal-level simultaneously, as well as a self-control performance measurement as a dependent variable are rare.

The term "ego-depletion" refers to a situationally reduced capability to execute self-control successfully and is based on the limited resource model of willpower (Baumeister, 2002; Baumeister et al., 1998; Muraven \& Baumeister, 2000). This model assumes that all acts of self-control draw on a general limited mental resource. Research in this domain had shown that ego-depletion can be evoked by different experimental interventions. Although the assumptions of the self-control strength model were confirmed by an enormous number of studies, since the seminal publication of the ego-depletion phenomenon by the Baumeister research team (Baumeister et al., 1998; Baumeister et al., 1994) there were also substantial studies with contradictory observations (Carter et al., 2015; Lurquin et al., 2016; 
$\mathrm{Xu}$ et al., 2014). Consequently a controversy has arisen on the question if the ego-depletion effect is real or not (Friese et al., 2019). This debate is also known as part of the replication crisis of psychology (Baumeister, 2019; Inzlicht \& Friese, 2019) and has initiated several preregistered replication studies (Dang et al., 2017; Dang et al., 2021; Hagger et al., 2016).

Many studies relevant to the replicability of the egodepletion effect focused on conceptual question of the self-control strength model (Inzlicht \& Schmeichel, 2012; Lurquin \& Miyake, 2017; Shenhav et al., 2017). Beside these conceptual discussions, several studies addressed the replication problems of ego-depletion focus either on research and publication practices (Carter \& McCullough, 2014; Vadillo, 2019; Wolff et al., 2018) or on the efficiency and adequateness of specific ego-depletion manipulations (Baumeister, \& Vohs, 2016; Lee et al., 2016). We would like to emphasize that all three paths of research are necessary to tackle these unresolved questions. Moreover, we argue that empirical studies, testing the boundaries and context factors of the self-control strength model by combining it with other relevant theories as in example the construal level theory (Trope \& Liberman, 2010), or the regulatory fit model (Higgins, 1998) are necessary. There is a need to further understand the role of high and low construal level, which has already been shown in prior studies, to be substantial for the success or failure of self-control performance. In particular the possibility that the involvement of constructs such as construal-level can contribute to a better understanding of inconsistent findings can help disentangling the aforementioned open questions.

The findings of the study by Schmeichel and Vohs (2009; Experiment 4) supported the role of high vs. low construallevel within the ego-depletion paradigm. This study used a standardized manipulation of abstract vs. concrete mind-set of Freitas et al. (2004) in the domain of delayed gratification (Metcalfe \& Mischel, 1999). Wan \& Agrawal (2011) were able to demonstrate in six experiments that the influence of ego-depletion on choices and decisions was mediated by the construal-level. The limitation of their study was however, that the choice between a low-construal and a high-construal option did not reflect self-control execution in the strict sense. The study by Agrawal \& Wan (2009) suggested that decreased self-control performance under concrete low construal-level after the execution of self-control can be traced back to the enhanced awareness of the limited resources of self-control. Nevertheless, the study was highly focused on the health domain and used a depletion manipulation that can also be understood as a cognitive load reading information on Hepatitis C-transmissions. In addition, the depletion may have been an effect of the health topic, which could raised fears and led to emotional deterioration.
In the current study we intend to investigate the influence of construal-level on self-control achievement of individuals under ego-depletion by drawing on previous studies (Agrawal \& Wan, 2009; Schmeichel \& Vohs, 2009; Schmeichel et al., 2011; Wan \& Agrawal, 2011). We extend this body of research by varying the construal-level before and after participants worked on an ego- vs. non ego-depletion inducing task.

Our hypotheses are:

1. A high construal level inhibits the ego depletion effect when manipulated before the ego depletion task.

2. A high construal level does not have an inhibiting effect on ego depletion when manipulated after the ego depletion task.

One way to test the correctness of our assumptions is to induce a different construal-level (high versus low) before or after a depleting task (vs. a non-depleting task) and subsequently measure the self-control performance/achievement in a final self-control task. This is in line with the sequential task paradigm of the ego-depletion research, enriched by the mentioned construal-level manipulation either before or after the ego-depletion manipulation. If an attentional shift away from the decreasing self-control resources is responsible for the higher self-control performance/achievement under a high construal-level, this should occur independently from the sequence of ego-depletion and construal-level manipulations. If the construal-level alters the way itself of how selfcontrol is executed the offset of ego-depletion should only be observed if a high construal-level is induced before the potential depleting task, but not if it is induced after the task.

\section{Execution of Self-Control in a Stroop-Task under High and Low Construal-Level}

A high construal-level should facilitate the application of a rule, compared to a low-construal level when individuals are more concerned with the effortful inhibition of the dominant habit. An abstract or unusual rule, such as the naming of the font color of the word as quickly as possible, while ignoring the literal meaning, is feasible and effortless under high construal-level, but would involve effortful inhibition under low-construal-level. The font color either matches (congruent trial) or does not match (incongruent trial) the literal meaning of the word.

The stroop test implies that participants are able to adopt an approach to internalize the rule to press 1 for red, 2 for green and 3 for yellow and to fade out the literal meanings of the word red, green and blue. Conventional explanation operates more at a concrete level, so 
that the participants have to stop the dominant behavioral option (reading) and execute the weak behavioral option (identifying font colors). The overriding of these automatic responses (reading) is much more effortful than the assumed automatic spontaneous implementation of an unusual behavioral-rule ("denominating three colors by $1,2,3$ and ignore literal meanings for a while").

The two potential paths of coping with the stroop task might be 1. to fade out the dominant behavioral response i.e. effortful "reading" 2. to apply a rule similar to a behavioral intention that enables a more automatic processing without using substantial self-control resources. We assume, that the latter is more probable in the state of an abstract mind-set, because an abstract mind-set enables better long-term goal guided processing and is more adequate for the adoption of an unusual rule to process the non-dominating but requested response in a stroop task (identifying font colors).

We assume that the execution of an incongruent stroop test is less effortful when processed under an abstract mindset, because this mental state is less affected by the concrete stimuli and enables a more fluent execution of an unusual new adopted rule. In addition, a study by Webb and Sheeran (2003) showed that participants instructed to use an implementation intention by immediately ignoring the literal meaning of the presented word and naming instead it's font color, prevents them of being depleted in a subsequent selfcontrol measurement. Moreover, we agree with the reasoning of Bruyneel and Dewitte (2012), that the experiments used by Wan and Agrawal (2011) with respect to the influence of ego-depletion on decision mediated by construallevel display an indirect measurement. The studies used judges and choices, reflecting high or low construal-level and high or low self-control decisions respectively.

Therefore this study uses an actual direct measurement of the execution of self-control as dependent measurement with an ego-depletion and a construal-level manipulation, in line with the suggestion of Fujita, Henderson, et al. (2006), Fujita, Trope, et al. (2006) who stated that the preference for low-construal versus high construal has to be distinguished from the actual execution of one option. The rationale is that the preference for a high construal-option does not necessarily imply that the individual at stake is able or motivated to actually execute it. Furthermore, we varied the sequence of both manipulations.

\section{Inducing the Construal-Level before and after a Depleting Task}

Contrary to previous explanations that are mainly based on attention shifts away from reduced self-control resources (Agrawal \& Wan, 2009; Wan \& Agrawal, 2011), we considered that different mind-sets would change the subsequent execution of self-control. This variation of the preand post-manipulation of the construal-level before and after the depleting stroop test enables us to test the outlined assumption of an altered way of executing self-control. If the underlying crucial mechanism is the altered execution of self-control in the first self-control task (stroop test) as described, it should offset the ego-depletion effect in the second self-control task if a high construal-level is induced before the stroop test. In contrast, a pure attentional shift away from the limited resources of self-control under high construal-level should be independent from the sequence of the manipulations.

\section{Experiment 1}

\section{Methods}

\section{Participants}

195 students (93 female) of the University of Mannheim, Germany took part in the experiment $\left(M_{\mathrm{age}}=22.1\right.$ years; $S D=3.1)$. They were rewarded with 5 EUR. The experiments took place within group sessions of 2 to 6 students and were conducted by two female supervisors.

\section{Procedures}

The abstract vs. concrete mind-sets were induced by a standard-procedure, in accordance with Freitas et al. (2004). In this task, the participants were asked how they would engage in health prevention behavior or why they would engage in health prevention. As in the original procedure, empty boxes were provided, starting from bottom-up (abstract mindset) or top-down (concrete mind-set) in which the answers should be written. We used the same instruction text as in the study of Freitas et al. (2004). The original materials were translated into German and afterwards double-checked by two bilinguals. To avoid any potential disturbance effects of formal versus familiar language on the construal-level we also varied the formal you, as "Sie" and the informal you as "Du" in the German language by using the formal form in the abstract condition and the informal one in the concrete condition.

As a standard ego-depletion inducing manipulation task, a stroop color procedure was used to induce the state of ego-depletion (50 trials incongruent in the ego-depletion manipulation vs. 50 congruent (same meaning and same color) trials in the control condition. This variation of the stroop color task is in widespread use within the ego-depletion literature and is being accepted as a standard procedure for inducing ego-depletion. But due to the replication 
problems of the ego-depletion effect, it is necessary to carefully choose a reliable ego-depletion task, which might be able to actually induce the intended effect. Baumeister and Vohs (2016) criticized how the manipulation of egodepletion was operationalized in the Hagger et al. (2016) replication study, mostly because of the lack of a training phase in which a habit could been established. Garrison et al. (2019, p.728) summarized: "Unlike many previous experiments [...], participants in the Hagger et al. study did not first establish a habit of responding to all e's before attempting to follow the more complicated rules. Thus, participants in the multi-lab replication study may not have needed to override a predominant response tendency-a crucial precondition for inducing ego depletion." Although the logic of suppressing a behavioral habit effortful in order to induce the state of ego-depletion is the same as in the e-letter task, the use of a color-stroop test is beneficial from the point of view of the already culturally strong established habit of reading. Thus, a corresponding training phase is not necessary and it can be surely assumed that the habit of reading is stronger than any newly learned rule. Consequently, more self-control might be applied to override this habit. Nonetheless, to ensure that the manipulation will be strong enough, we slightly modified the incongruent condition by inserting a number of "reversed" stimuli in which the participant had to identify the meaning of the word rather than the color. The task was indicated by a box around the written word. The incongruent character (color and meaning are not same) of the stimuli remained in both versions of the ego-depletion condition. In the nonego depletion condition, all stimuli were congruent (same color and meaning of the words.). This kind of color-stroop test in the ego-depletion condition is in accordance with approaches which emphasize that the change between different tasks or between different rules is probably one of efficient depleting manipulations. This can be concluded for example from a Study by Yan et al. (2018) who argue that shifting between different mental tasks can have a substantial depleting effect similar as the switching between mind-sets or languages. Furthermore, this reasoning is being supported by Rogers and Monsell (1995) as well as by Monsell (2003). We used the next-trial-after-anyresponse configuration and set no time-limitation for the responses. The sequence of conventional and reversed stimuli was random. The number of reversed stimuli in the ego-depletion condition also varied random-based slightly between 12 and $19(M=15.8 ; S D=1.9)$ out of the 50 trials.

For the second independent variable we altered the sequence of the 2 (abstract vs. concrete mind-set) by 2 (egodepletion vs. no ego-depletion) design. About $50 \%$ of the participants received the ego-depletion manipulation first and the construal-level manipulation subsequently and the rest received the manipulations in the reversed order (cf. Figure 1.)
Experiment 1 with ego-depletion manipulation first

Experiment 1 with construal-level manipulation first

Expriment 2 with construal-level manipulation first
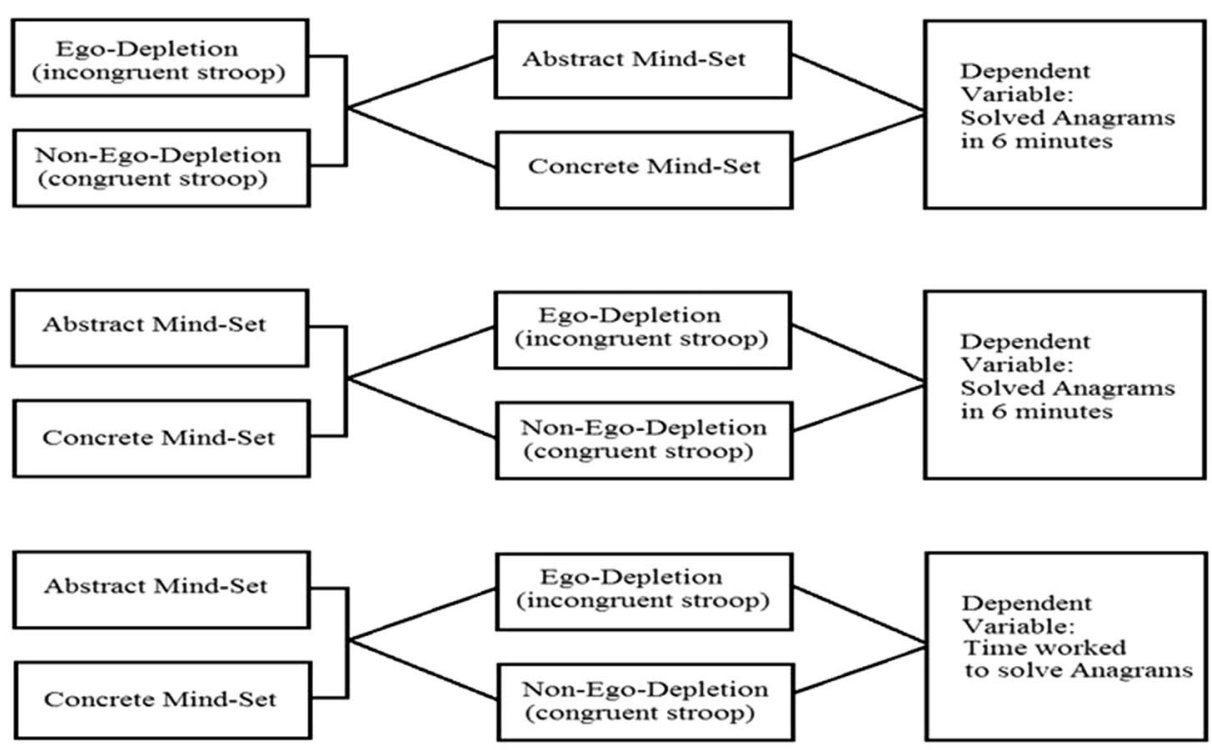

Summary of hypothesis:

1. A high construal level inhibits the ego depletion effect when manipulated before the ego depletion task. (tested in Experiment 1 and 2)

2. A high construal level does not have an inhibiting effect on ego depletion when manipulated after the ego depletion task. (tested in Experiment 1)

Fig. 1 The experimental design and summary of hypothesis of Experiment 1 (with the two sequences) and Experiment 2 
In all experimental conditions, the participants filled out one question on their current situational self-control strength, as a manipulation check, directly after completing the stroop task. The wording of the item was (a) "How efficient do you feel right now?" In the following, we refer to this item as "self-reported efficiency". High values indicate a high level of reported self-control resources. Afterwards, all participants received the same anagram task, which was delivered on one single page as a list of twenty-six anagrams, each with a blank space on the right side, for writing the correct answer. This anagram task was used to measure self-control performance. According to Baumeister et al. (2006, p. 1785) solving anagrams requires self-control, since "[...] there is no simple algorithm for solving an anagram; instead, one must create novel combinations and then disassemble them to try something else." Other studies also applied anagrams successfully as dependent measurement of self-control (Bertrams \& Schmeichel, 2014; Muraven et al., 2006). The participants had 6 min to solve as many anagrams as possible. All anagrams used, were names of animals (e.g. BERIB = BIBER; PRAFNEK $=$ KARPFEN; English equivalents: VREBAE $=$ BEAVER; PRCA $=$ CARP). We used the number of solved difficult anagrams as dependent measurement of self-control performance (cf. Uziel \& Baumeister, 2017). We decided to use easy and difficult anagrams, to avoid suspicion by participants regarding the solvability of the anagrams if only difficult ones were used. Thus, the easy anagrams served as filler tasks. We choose the task of solving anagrams because it requires a focus on detailed stimuli and can be clearly evaluated as task with low-construal-level character. Thus, this measurement of self-control enables a critical testing of the assumed enhancing influence of construal-level on self-control performance. This way it can be ruled out that a high construal-level just fits better to the requirements of the used task. This enables the attribution of an enhanced performance under a high construal-level to enhanced self-control itself and not to some idiosyncratic features of the task. Approximately half of the presented anagrams were considered as difficult, as it was assumed that only the solution of difficult anagrams requires self-control. The categorization was based on a pretest of 56 students from the same University as in the main experiment. Based on a median split we classified 13 out of 26 anagrams as difficult ( $M d n=28$ correct solved anagrams). All anagrams, which were solved 28 times or less frequently were classified as difficult, all others solved more frequently than 28 times as easy. The percentage of correctly solved anagrams was $34.3 \%(S D=11.3 \%)$ for the difficult and $72.2 \%(S D=15.2 \%)$ for the easy anagrams. The remaining easy anagrams were used as filler task items. This classification was additionally controlled by the observed correct response rate in the main experiment: The rate of anagrams being solved vs. not solved in Experiment 1 was $29.1 \%$ (difficult) vs. $66.5 \%$ (easy) and in Experiment 2 with no time limitation 50.5\% (difficult) vs $77.0 \%$ (easy), indicating a correct classification.

After exactly $6 \mathrm{~min}$, the task was stopped and the postexperimental questionnaires, including manipulation-checks (the short version of the German Situational Self-Control Capacity Scale (SSCCS) by Bertrams et al., 2011); and sociodemographic information (gender, age, field of study) were filled out by the participants. Subsequently the participants were debriefed and released. In the following, we refer to German short version of the Situational Self-Control Capacity Scale as SSCCS (with a sum index of the 10-item scale). High values indicate high perceived available resources of self-control.

\section{Results}

\section{Data Analysis}

\section{Manipulation Checks}

The first manipulation check consisted of an item directly after the ego-depletion inducing stroop test, which measured "self-reported efficiency". Moreover, we applied the validated German short version of the Situational-Self-ControlCapacity-Scale (Bertrams et al., 2011), which was placed at the end of the experiment. We conducted ANOVAs on both measurements with construal-level and ego-depletion as factors (cf. Table 1).

For the condition in which the construal-level was manipulated first, we observed no significant main effect for construal-level and ego-depletion on "self-reported efficiency"; (all $p$ 's $>0.362$ ). The corresponding interaction did also not reach significance $(p=0.465)$. In line with these results there were no significant effects neither for both main effects, nor for their interactions on the sum index of SSCCS; all $p$ 's $>0.373$.

For the condition in which the construal-level was the second manipulation, we observed a significant main effect $(p=0.007)$ of ego-depletion on "self-reported efficiency" in the predicted direction that indicated lower perceived resources under ego-depletion $\left(M_{\text {EGO-DEPLETION }}=4.63\right.$; $S D=1.39$ vs $\left.M_{\text {NON-EGO-DEPLETION }}=5.33 ; S D=1.06\right)$. The results of the corresponding ANOVA with significant main effect for ego-depletion on "self-reported efficiency" was as follows; $F(1,93)=7.49 ; p=0.007 ; \eta^{2}=0.08$ (all $p$ 's are reported for two-tailed tests). We also observed a non-significant tendency of the main effect for egodepletion $(p=0.064)$ on the SSCCS. Again, those in the ego-depletion condition reported less available selfcontrol resources $\left(M_{\text {EGO-DEPLETION }}=4.79 ; S D=1.11\right.$ vs. $M_{\text {NON-EGO-DEPLETION }}=5.18 ; S D=0.92$ ). The corresponding results of the ANOVA for ego-depletion on the sum-index 
Table 1 ANOVA for ConstrualLevel (CL) and Ego-Depletion (ED) on self-reported efficiency and the German short version of the Situational Self-Control Capacity Scale (SSCCS)

\begin{tabular}{|c|c|c|c|c|c|c|}
\hline Source & & $d f$ & $M S$ & $F$ & $p$ & $\eta_{P}^{2}$ \\
\hline & \multicolumn{6}{|c|}{ for self-reported efficiency: } \\
\hline \multicolumn{7}{|c|}{ Construal-level first } \\
\hline & Construal-Level (CL) & 1 & 0.21 & 0.12 & .727 & .001 \\
\hline & Ego-Depletion (ED) & 1 & 1.40 & 0.84 & .363 & .009 \\
\hline & CL x ED & 1 & 0.90 & 0.54 & .469 & .006 \\
\hline & Within-cells errors & 94 & 1.67 & & & \\
\hline \multicolumn{7}{|c|}{ Ego-depletion first } \\
\hline & Construal-Level (CL) & 1 & 0.01 & 0.00 & .972 & .000 \\
\hline & Ego-Depletion (ED) & 1 & 11.76 & 7.49 & .007 & .075 \\
\hline & CL x ED & 1 & 0.00 & 0.00 & .986 & .000 \\
\hline & Within-cells errors & 94 & 1.57 & & & \\
\hline \multicolumn{7}{|c|}{ for Situational Self-Control Capacity Scale (SSCCS): } \\
\hline \multicolumn{7}{|c|}{ Construal-level first } \\
\hline & Construal-Level (CL) & 1 & 1.53 & 0.80 & .372 & .009 \\
\hline & Ego-Depletion (ED) & 1 & 0.15 & 0.01 & .929 & .000 \\
\hline & CL x ED & 1 & 0.18 & 0.09 & .469 & .001 \\
\hline & Within-cells errors & 93 & 1.92 & & & \\
\hline \multicolumn{7}{|c|}{ Ego-depletion first } \\
\hline & Construal-Level (CL) & 1 & 0.09 & 0.09 & .765 & .001 \\
\hline & Ego-Depletion (ED) & 1 & 3.52 & 3.52 & .064 & .036 \\
\hline & CL x ED & 1 & 1.00 & 6.19 & .015 & .062 \\
\hline & Within-cells errors & 93 & 1.57 & & & \\
\hline
\end{tabular}

All p's are for two-tailed tests; $\mathrm{R}^{2}=.045 . ; \mathrm{R}^{2}=.010 . ; \mathrm{R}^{2}=.010 . ; \mathrm{R}^{2}=.097$ of SSCCS were: $F(1,93)=3.51 ; p=0.064 ; \eta_{\mathrm{P}}^{2}=0.036$. We further observed a significant interaction of construallevel-level by ego-depletion on SSCCS; $F(2,93)=6.18$; $p=0.015 ; \eta_{\mathrm{P}}^{2}=0.062$. Post-hoc analysis revealed that the difference under low construal $\left(M_{\text {EGO-DEPLETION }}=4.55\right.$, $S D=1.09$ vs. $M_{\text {NON-EGO-DEPLETION }}=5.44 ; S D=0.88$ ) shows a non-significant tendency $(p=0.060)$ for the two-tailed test, whereas the difference under high construal-level $\left(M_{\text {EGO-DEPLETION }}=5.00, S D=1.11\right.$ vs. $\left.M_{\text {NON-EGO-DEPLETION }}=4.87 ; S D=0.88\right)$ disappeared $(p=0.210)$.

The manipulation check for the construal-level was based on four independent raters, who rated each of the responses and which were blind to the purpose of the current study on a scale ranging from 1 ("very concrete") to 5 ("very abstract"). This procedure was adopted from Freitas et al. (2004). The mean-differences of all ratings clearly indicated a successful construal-level manipulation with higher values in the abstract/high construal-level conditions for both sequences $\left(M_{\text {high }}=3.53 ; S D=0.65\right.$ vs. $M_{\text {low }}=2.13 ; S D=0.45 ; p<0.001$ if construal-level was manipulated second and $M_{\mathrm{high}}=3.45 ; S D=0.59$ vs. $M_{\text {low }}=2.18 ; S D=0.55 ; p<0.001$ if construal-level was manipulated first). In line two conducted ANOVAs revealed significant main effects of construal-level on rated abstraction vs. concreteness for the rank-order construallevel second; $F(1,95)=148.87 ; p<0.001 ; \eta_{\mathrm{P}}^{2}=0.610$, and for the one with construal-level first; $F(1,96)=121.29$; $p<0.001 ; \eta_{\mathrm{P}}^{2}=0.558$.

\section{Main Analysis}

We conducted a separate ANOVA for each of the two sequences, with the factors ego-depletion and construallevel. The ANOVA with the construal-level manipulation (why vs. how-task) second, revealed a "very nearby" significant main effect for ego-depletion; $F(1,93)=3.92 ; p=0.051$; $\eta_{\mathrm{P}}^{2}=0.040$ for the two-tailed tests. Those participants who worked on the congruent stroop task solved a significantly higher number of difficult anagrams $(M=4.70 ; S D=3.07)$ compared to those who worked on the incongruent version $(M=3.57 ; S D=2.34)$. Neither the main-effect of construallevel, nor its interaction with ego-depletion was significant, all $p$ 's $>0.311$ (cf. Table 2 and Fig. 2).

When the sequence was turned into construal-level manipulation (why vs. how-task) first, the same ANOVA revealed a non-significant tendency for construal-level; $\left(F(1,94)=3.19 ; p=0.077 ; \eta_{\mathrm{P}}^{2}=0.033\right)$, whereas no significant ego-depletion main effect at all was observed any 
Table 2 ANOVA for ConstrualLevel (CL) and Ego-Depletion (ED) on Solved Difficult anagrams when Construal-level was manipulated second

\begin{tabular}{|c|c|c|c|c|c|c|}
\hline Source & & $d f$ & $M S$ & $F$ & $p$ & $\eta_{P}^{2}$ \\
\hline & Construal-Level (CL) & 1 & 1.85 & 0.25 & .618 & .003 \\
\hline & Ego-Depletion (ED) & 1 & 29.04 & 3.92 & .051 & .040 \\
\hline & CL x ED & 1 & 7.66 & 1.03 & .312 & .011 \\
\hline & Within-cells errors & 93 & 7.41 & & & \\
\hline
\end{tabular}

All $p$ 's are for two-tailed tests; $R^{2}=.055$ longer $\left(F(1,94)=1.58 ; p=0.212 ; \eta^{2}=0.016\right)$. Again, the two-way interaction of both factors did not reach significance $(p>0.742)$ (cf. Table 3 and Fig. 3).

We further tested the three-way interaction with the dependent variable of difficult solved anagrams by collapsing all data of Experiment 1 to have a more straightforward testing of our hypotheses. Thus we conducted an ANOVA with ego depletion, construal level and sequence (construal level manipulation first vs. ego depletion manipulation first). First the ego depletion effect reached significance; $F(1,187)=5.30$; $p=0.022 ; \eta^{2} \mathrm{P}=, 028$. Second the hypothesized three-way interaction did not reach significance; $F(3,184)=0.93$; $p=0.336 ; \eta^{2} \mathrm{P}=0.005$. This is contradictory to the observations if analyzing the two sequences separately, in which we found a significant ego-depletion effect if the construal-level observation preceded the ego-depletion manipulation and a disappearance of the ego-depletion effect if a high construallevel was induced prior to the ego-depletion manipulation.

\section{Discussion}

The results of Experiment 1 showed that the ego-depletion was offset if a high construal-level was induced before an incongruent stroop-test but not if it was induced after the depleting incongruent stroop-test. To ensure that the offset of ego-depletion by a prior induced high construal-level is also observable with another dependent self-control measurement and in order to retest our first hypothesis, we conducted Experiment 2. Instead of the measurement of selfcontrol as the number of correct solved difficult anagrams within a time limit, we applied a more reliable measure of self-control in Experiment 2, which is a persistence measure in the same anagram task without a time limit. Experiment 2 was also designed to rule out the alternative explanation that individuals under high construal-level show better self-control because they shift their attention away from the exhausted resources of self-control.
Fig. 2 Number of solved difficult anagrams Ego-Depletion by Construal-Level with ConsturalLevel manipulation second; error bars show standard errors

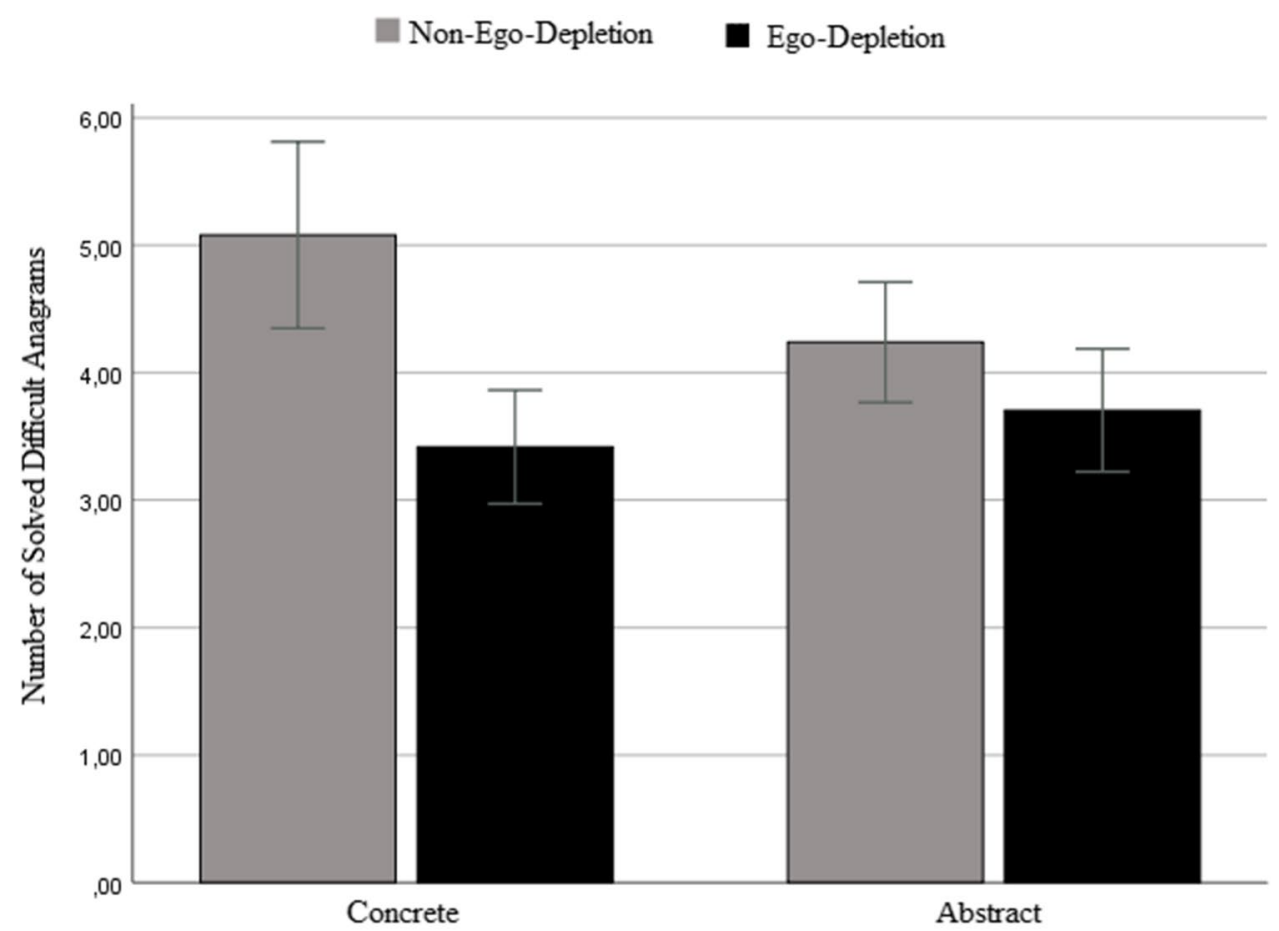

Mind-Set 
Table 3 ANOVA for ConstrualLevel (CL) and Ego-Depletion (ED) on Solved Difficult Anagrams when Construal-level was manipulated first

\begin{tabular}{|c|c|c|c|c|c|c|}
\hline Source & & $d f$ & $M S$ & $F$ & $p$ & $\eta_{P}^{2}$ \\
\hline & Construal-Level (CL) & 1 & 21.50 & 3.19 & .077 & .033 \\
\hline & Ego-Depletion (ED) & 1 & 10.61 & 1.58 & .212 & .016 \\
\hline & CL x ED & 1 & 0.73 & 0.11 & .743 & .001 \\
\hline & Within-cells errors & 9 & 6.73 & & & \\
\hline
\end{tabular}

All $p$ 's are for two-tailed tests; $R^{2}=.048$
We measured for this purpose the overoptimism for the dependent variable, which should be enhanced under high construal-level if participants shift their attention away from their exhausted resources of self-control.

\section{Experiment 2}

Persistence on difficult or boring tasks can be considered as one of the most reliable measurements of willpower. To establish this kind of measurement, we again used the same anagram task, but without time-limitation. Instead, the participants were informed that they could work on the task, as long as they liked. Our main dependent measurement was the time each participant took for the anagram task. In addition, we measured the number of the difficult anagrams as in Experiment 1. We took however into account, that the number would be highly depending on the time until giving up on the task. All other parts of the procedure and materials were the same as in the first experiment. We expected, in line with our first hypothesis that participants with a high construal-level will work significantly longer on the task without being affected by the ego-depletion manipulated.

\section{Methods}

\section{Participants}

Eighty students (57 female) of the University of Mannheim, Germany took part in the second experiment in exchange for 5 EUR under the same conditions as in Experiment 1 $\left(M_{\text {age }}=21.6\right.$ years; $S D=2.6$ ).

\section{Procedures}

In Experiment 2, we replicated the sequence condition with the manipulation of construal-level first to test if the
Fig. 3 Number of solved difficult anagrams Ego-Depletion and Construal-Level with Construal-Level manipulation first; error bars show standard errors

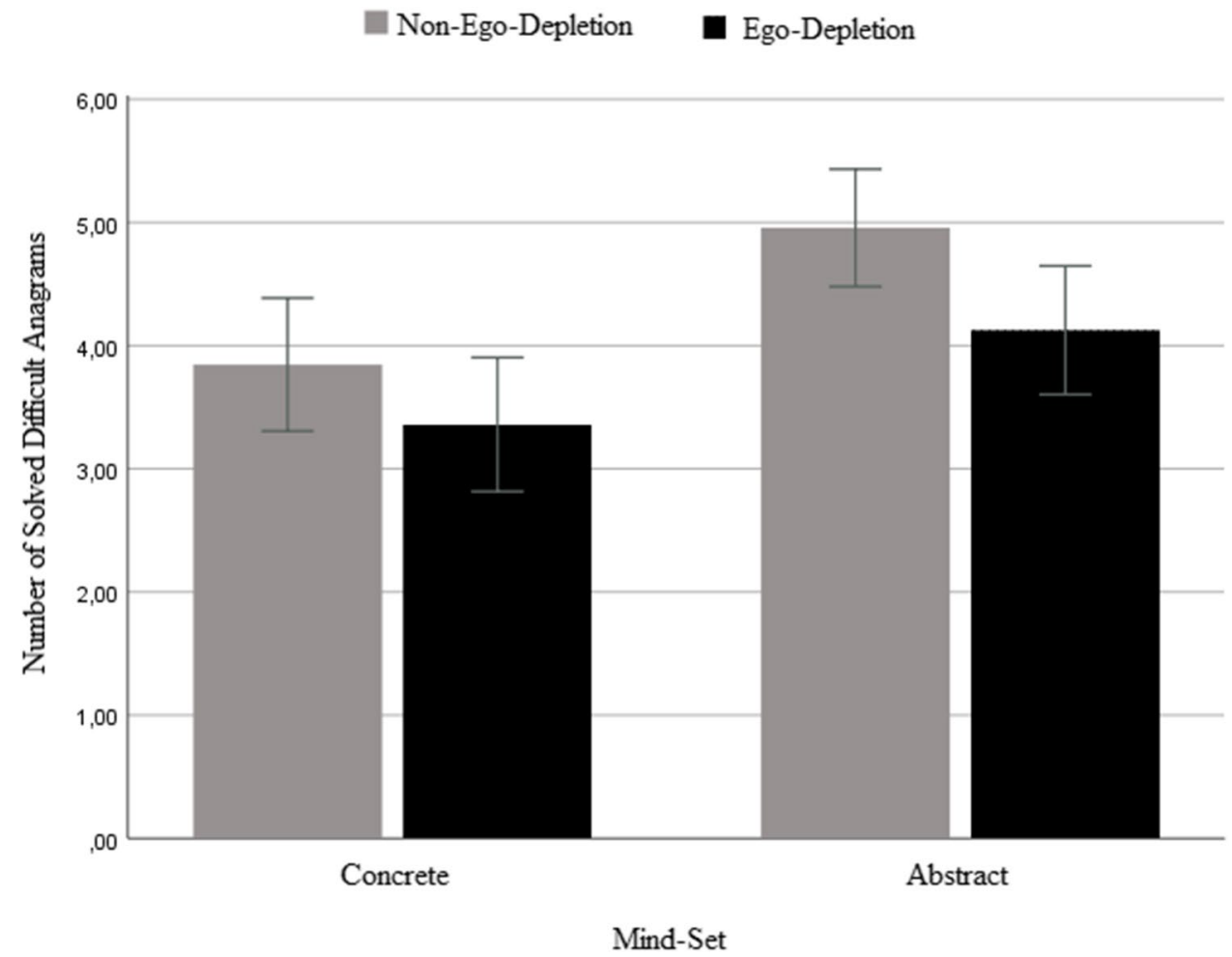


ego-depletion effect is also offset when a persistence measurement of self-control is used as a dependent variable. To test our assumption that a high construal-level will reduce and not enhance the estimated achievement in the anagram task, the participant were asked following question before starting this task: "What is your estimate on your results in the anagram task ranging from 1 (=very bad) to 10 $(=$ very good)?" All other procedures were identical to Experiment 1 . The corresponding random-based number of reversed stimuli in the ego-depletion condition varied between $12-19(M=16.2 ; S D=2.1)$.

\section{Results}

\section{Data Analysis}

\section{Manipulation Checks}

Similarly to the equivalent sequence in Experiment 1 we did not observe any significant main effects of egodepletion on neither "self-reported efficiency" nor SSCCS; (all $p$ 's $>0.150$ ). In addition, no main effects of construallevel and no interaction of construal-level by ego-depletion on SSCCS were observed; (all $p$ 's > 0.332). See for both analysis Table 4.

Table 4 ANOVA for ConstrualLevel (CL) and Ego-Depletion (ED) on self-reported efficiency and the German short version of the Situational Self-Control Capacity Scale (SSCCS)
Table 5 ANOVA for Construallevel (CL) and Ego-Depletion (ED) on the persistence in solving anagrams
Finally, we tested the manipulation of the construallevel by the same rater-method as in Experiment 1 . Again, the manipulation was significant. The main effect of construal-level reached significance; $(F(1,78)=74.21$; $\left.p<0.001 ; \eta_{\mathrm{P}}^{2}=0.488\right)$ with higher rated abstractness in the high construal condition $(M=3.29 ; S D=0.70)$ compared to the low construal condition $(M=2.14 ; S D=0.48)$.

\section{Main Analysis}

We first conducted an ANOVA with the factors construal-level and ego-depletion on persistence in solving anagrams. As predicted, we observed a main effect of construal-level; $\left(F(1,76)=8.96 ; p=0.004 ; \eta^{2}=0.105\right)$, whereas the main effect of ego-depletion and the two-way interaction did not reach significance; (all $p$ 's $>0.439$; cf. Table 5). As illustrated in Fig. 4 those in the abstract conditions showed more persistence, compared to their counterparts in the concrete conditions independently from ego-depletion.

We conducted an ANOVA with the same difficult anagrams as in Experiment 1 which made up the dependent variable, considering however that the number was highly related to the time worked on the task. The results indicated that as in Experiment 1 construal-level showed a non-significant tendency in the predicted direction at the two-tailed level when construal-level was manipulated first; $\left(F(1,75)=2.94 ; p=0.091 ; \eta^{2}=0.038\right)$. No other effects

\begin{tabular}{llllll}
\hline Source & $d f$ & $M S$ & $F$ & $p$ & $\eta_{\mathrm{P}}^{2}$ \\
\hline $\begin{array}{l}\text { for self-reported efficiency: } \\
\text { Construal-level first }\end{array}$ & & & & & \\
Construal-Level (CL) & 1 & 1.56 & 1.21 & .274 & .016 \\
Ego-Depletion (ED) & 1 & 0.50 & 0.39 & .534 & .005 \\
CL x ED & 1 & 2.33 & 1.81 & .183 & .023 \\
Within-cells errors & 76 & 1.29 & & & \\
& & & & & \\
for Situational Self-Control Capacity Scale (SSCCS): & & & \\
Construal-level first & & & & & \\
Construal-Level (CL & 1 & 0.72 & 0.69 & .410 & .009 \\
Ego-Depletion (ED) & 1 & 0.19 & 0.18 & .672 & .002 \\
CL x ED & 1 & 0.99 & 0.95 & .333 & .012 \\
Within-cells errors & 76 & 1.04 & & & \\
\hline
\end{tabular}

All $p$ 's are for two-tailed tests; $\mathrm{R}^{2}=.043$.; $\mathrm{R}^{2}=.024$

\begin{tabular}{|c|c|c|c|c|c|c|}
\hline Source & & $d f$ & $M S$ & $F$ & $p$ & $\eta_{P}^{2}$ \\
\hline & Construal-Level (CL) & 1 & 328.64 & 8.96 & .004 & .105 \\
\hline & Ego-Depletion (ED) & 1 & 6.15 & 0.17 & .646 & .002 \\
\hline & CL $x$ ED & 1 & 21.26 & 0.58 & .440 & .008 \\
\hline & Within-cells errors & 76 & 36.68 & & & \\
\hline
\end{tabular}

All $p$ 's are for two-tailed tests; $R^{2}=.113$ 
Fig. 4 Time worked on the task in minutes, by Ego-Depletion and Construal-level with Construal-Level manipulation first; error bars show standard errors
Non-Ego-Depletion ago-Depletion

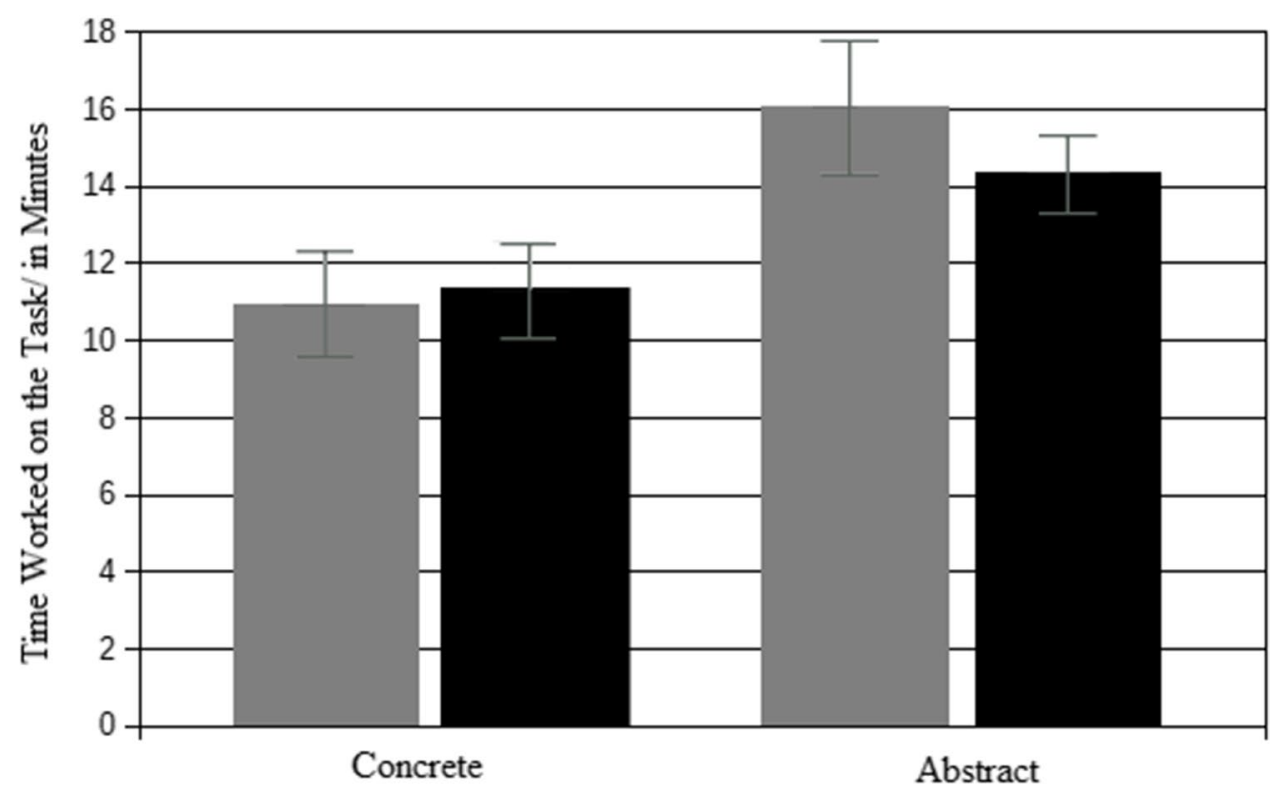

Mind-Set

were observed (cf. Table 6). If we conducted the same ANOVA controlling for time by including this variable as covariate construal-level did not reach significance, whereas ego-depletion and the interaction remained also insignificant (all $p$ 's $>0.291$ ). Most important as assumed no ego-depletion effect was observed on the number of difficult anagrams.

Further we calculated the ratio between the prior estimation of achievement and the actual overall solved anagrams. To standardize the different measurement-units we transformed both variables into t-scores and then divided the estimations by the actual overall solved anagrams on the task. This ratio represented the degree of over-optimism. We conducted an ANOVA with construal-level and ego-depletion on over-optimism. We observed for the twotailed test a non-significant tendency of of construal-level; $F(1,76)=3.33, p=0.072, \eta_{\mathrm{P}}^{2}=0.043$. Ego-depletion and the interaction did not reach significance (all $p$ 's $>0.528$ ). Under high construal-level the participants tending to show less over-optimism ( $\left.M_{\text {high }}=0.97 ; S D=0.20\right)$ compared to those under the low construal condition $\left(M_{\text {low }}=1.08 ; S D=0.32\right)$.
This difference only reached significance for the one-tailed test $(p=0.036)$.

\section{Discussion}

The main result of Experiment 2 was that the ego-depletion effect was offset when the construal level was manipulated first, even when we used a persistence measurement, instead of the solving-rate of difficult anagrams. If an attention shift away from reduced self-control resources is responsible for the better self-control under the high construal condition, this should result in a higher and not lower over-optimism. However, in line with prior reported studies, we observed a significant decrease of over-optimism under high selfconstrual. Thus, we can rule out that an altered focus on the reduced self-control resources are responsible for the improved self-control performance under high construallevel. Experiment 2 also shows evidence that a shift away from the exhausted self-control resources under high
Table 6 ANOVA for Construallevel (CL) and Ego-Depletion (ED) on solved difficult anagrams

\begin{tabular}{llllll}
\hline Source & $d f$ & $M S$ & $F$ & $p$ & $\eta_{\mathrm{P}}^{2}$ \\
\hline Construal-level (CL) & 1 & 40.94 & 2.94 & .091 & .038 \\
Ego-Depletion (ED) & 1 & 0.33 & 0.02 & .877 & .000 \\
CL x ED & 1 & 13.57 & 0.97 & .327 & .013 \\
Within-cells errors & 75 & 13.93 & & & \\
\hline
\end{tabular}

All $p$ 's are for two-tailed tests; $R^{2}=.048$ 
construal-level can be excluded as an explanation: Under high construal-level over-optimism was reduced, which is in line with prior studies (Freitas et al., 2004; Yan et al., 2014).

\section{General Discussion}

The current study is the first one varying the sequence of ego-depletion and construal-level manipulation, using the same procedures for manipulation. What can be drawn from it is the important observation that sequence matters. We conclude preliminary that the way of executing selfcontrol might be altered when self-control is performed in a state of high construal-level (compared to a low construal-level). In contrast, once depleted, a following induced high construal-level is not able to improve selfcontrol performance in the final measurement. Thus, in contrast to the reversed sequence condition, no offset of ego-depletion effect was observed in Experiment 1.

A correction of the state of ego-depletion by inducing a high construal-level subsequently has been proven ineffective and useless. Our results are contradictory to those outlined studies with a construal manipulation between the two self-control tasks. Our observations are incompatible with an explanation relying on an enhanced focus on limited resources as a result of ego-depletion. If the enhanced awareness about limited resources would be indeed the underlying mediator, those in the abstract condition who had the ego-depletion manipulation first, should also perform better, compared to those in the concrete condition. Instead, we observed the known depleting effect of those who worked before on the incongruent version of the stroop test. Future studies are encouraged to test the suggested mechanism in a straightforward way.

We assumed that participants in the condition in which the high-contrual was induced prior to the ego-depletion manipulation, were driven by their high-construal mind-set in a more automatic way when worked at the stroop test. Such an automatic modus could be similar, but not identical to the approach of hypo-ego self-regulation (Leary et al., 2006). The difference is that the concept of hypo-ego self-regulation assumes concrete states as an escape from the self, whereas we assume that abstract states can also serve as an escape, in the sense of an abstraction from the concrete requirements of self-control. This approach seems to be backed up by the current results, which did not indicate a decrease in self-control. In contrast, the abstract mind-set seems to be more efficient because the individuals remain efficient in self-control performance in the subsequent self-control task.
More precisely, we assumed that self-control execution in an abstract mind-set is more automatic and thus more parsimonious towards resources of self-control. We suggest that self-control requests are located on a concrete level, whereas the consciousness of a person is focused on abstract issues or goals. This might change the working modus into being more guided by high-level concerns. One limitation of this explanation could be tasks requiring steady awareness and concentration. In the case of the stroop task as used in the current experiment, we however assumed that the adoption of a rule such as " 1 for red color, etc." is more efficiently executed if a person thinks abstractly. We are aware that these interpretations need more straightforward testing with experiments allowing a measurement of the underlying processes. For example, we do not test in the current study if individuals really adopt rules in order to override habitualized actions.

The abstraction could however be helpful: If a person adopts for example a fixed memorized rule as outlined, it might be more efficient and resource saving than if a person goes through each trial concentrating on ignoring the words, stop reading and shifting the concentration back to the colors.

From a more external and distanced view, or from a higher perspective, it seems to be easier to apply the new unusual rule effectively. In general, an abstract mind-set can be understood as a processing-modus, that focus on longterm higher-level goals and that might be describable as a flow-like exercising through the difficult tasks without being inhibited by the concrete details. The results of our study seem to imply that once stuck in the detail, the manipulation of a high construal-level is not helpful anymore to overcome this low state of construal evoked by the initial ego-depletion manipulation. This also rises the question on the mental costs of changing mind-sets, in particular from a low (concrete) to a high (abstract) construal-level.

The mind-set in which the self-control is executed (in the initial task) seems to be of high relevance. An approach explaining the changed self-control performance in the subsequent task merely by an attentional shift cannot account for the present observation that no improvement of selfcontrol was observed when the construal-level manipulation was introduced after the ego-depletion manipulation. If attentional shifts to the current availability of self-control resources would be the main underlying process, a high construal-level should affect the results by setting off the ego-depletion effect also in the condition with construallevel coming second. Attentional shifts away from diminished self-control resources should also result in improved self-control if evoked by high construal-level after the stroop 
tests. The analyses of the measured over-optimism in Experiment 2 further showed incompatible results with the attentional shift hypothesis by Agrawal and Wan (2009).

Moreover, our two current experiments are however not alone sufficient to test the assumptions on underling mediating or moderating mechanisms in comprehensiveness. It might, however open some possible future research paths and we highly recommend further testing the open questions of our argumentation. The main observation that a high construal-level is able to offset ego-depletion when it is induced first, but not when it is induced following the self-control execution, is in line with the idea that the way in which self-control is executed, might depend on abstractness of thinking. One possibility of an altered mode could be an automatization of those processes on a high construallevel and may thus reduce deliberate and effortful processes. Finally, future research might test the assumption of altered ways of executing self-control. Our observations seem to imply that self-control is executed under high-construal effectively without getting depleted.

\section{Limitations}

For the aforementioned reasons and because of the deviant results by Schmeichel et al. (2011), it is evident that more studies are needed to identify the conditions for these diverging effects. Schmeichel et al. point to the specification of the respective used self-control tasks, which were hitherto largely ignored. They mention in particular, that those tasks requiring a high degree of concentration and monitoring would be performed better under low construal as shown in their experiment. These authors together with Bruyneel and Dewitte (2012), suggest the further consideration of the specificities of the respective used self-control tasks and emphasize that future research should focus more on different types of self-control tasks, which differ in their compatibility to abstract/concrete construal-levels. These and related research efforts might be able to clarify some of the discussed open questions.

One important aspect arises from the results by Schmeichel et al. (2011) that imply enhanced self-control under low construal-level. Another path of research, which demonstrated advantages of concrete thinking for self-control under specific conditions, refers to a type of mind-set which is explicitly goal-related and issued in the Rubicon model of action phases (Keller et al., 2019). The central distinction between deliberative or decisional mind set versus a planning mind-set (Gollwitzer, 2012) deliver divergent predictions about the effects of mind-sets on self-control performance. The more concrete implemental mind-sets (planning mind-sets) facilitate self-control, if the self-control activity at stake is connected to reaching the corresponding goal by enhanced positive illusion and enhanced motivation. In contrast the more abstract deliberative mind-set has been found to be less beneficial, particularly when it is about persistence in goal directed action (Gollwitzer \& Bayer, 1999).

Thus, it is obvious that also concrete thinking under certain conditions - as specific mind-sets and requirements of the tasks - can improve self-control performance. Further our results are contradictory to the results by Schmeichel and Vohs (2009), who observed an offset of the ego-depletion effect in their Experiment 4, in which the construal-level was induced subsequently to an ego-depletion manipulation. Considering the high self-relevance of the construal-level in their study (What are you most important personal values?) it might be probable that construal-level manipulations differ in their effectiveness. Further Schmeichel and Vohs operationalized however the stroop-task as dependent measurement, whereas in our current experiments the stroop-task was used as manipulation of ego-depletion. This points to the importance to differentiate between the different requirements of self-control tasks (cf. Nguyen et al. (2019).

Another limitation is that we did not operationalize the sequence with the construal-level prior to the ego-depletion manipulation in Experiment 2. Thus, we highly recommend further experiments, which should also vary the used self-control tasks to ensure generalizability of the observed effects.

One of the main shortcomings of the current study is that the three-way interaction did not reach significance when the data of Experiment 1 with both sequences of manipulation were collapsed and analyzed together. Consequently we suggest future research to scrutinize the assumed mechanism. This should also include more and different manipulation and dependent measurements of self-control performance. What our study however has shown-in line with prior research-is that construal-level is one of the essential factors of influence which has to be considered when testing for the ego-depletion effect. The second implication of our study is that the sequence of the manipulation plays also a crucial role. More research about the complex interplay between mind-sets differing in their construal-level and ego-depletion might deliver important responses to the question if ego-depletion is real or not. The results of the current study deliver as already outlined some supporting hints for the assumption, that a high construal-level induced before an self-control exhausting task might prevent from becoming ego-depleted (see Experiment 1 with construallevel manipulated first and Experiment 2). On the other side once depleted by a prior self-control exhausting task, a high construal level seems than useless to "repair" the state of 
ego-depletion. The construal-level might explain some of the inconsistent findings of the ego-depletion research. We might also highlight that the idiosyncrasies of the applied self-control tasks should also further investigated. Presumably this approach is another necessary step among many other approaches to overcome the insecure and ambiguous data situation which is currently prevalent in the ego-depletion and self-control research. It is obvious that for this context the interplay between specific task characteristics and resulting theoretical implication is of high importance. This is about the question how self-control can it be operationlized and measured properly. A focus on this question might facilitate to differentiate between valid and invalid observations, which in turn can better reveal the prerequisites of an ego-depletion effect or showing that there is no at all as discussed currently in the replication crisis controversy. For our current study it is evident that replication studies with others ego-depletion manipulations and or other dependent measurements would be very helpful for further scrutinizing the tested hypotheses.

\section{Conclusions}

The abstract mode enabled participants to better cope with the contradictory stimuli of a color and its deviant meaning, because the higher psychic distance facilitated the application of a more abstract rule to indicate specific colors by specific numbers or by pushing specific buttons of the laptop, instead of carrying out the highly familiar action of reading. The difference to the effortful inhibition of reading as assumed for the low construal-level, is that, the self-control in a subsequent task will not be affected by ego-depletion, if the preceding self-control task is executed in an abstract high construal mind-set, induced in advance. In contrast, a mere inducement between both tasks has been shown to be inefficient in preventing ego-depletion. Further studies are however needed which shed more light on the assumed altered processes of self-control execution under high and low construal-level.

Funding Open Access funding enabled and organized by Projekt DEAL. The authors have no relevant financial or non-financial interests to disclose.

Data Availability The datasets generated during and/or analysed during the current study are available from the corresponding author on reasonable request.

\section{Declarations}

Ethical Standards Approval was granted by the applicable institutional research ethics committee of the IIMS Institute of the Ludwigshafen
University of Business and Society and attests that the study was performed in accordance with the ethical standards as set forth in the 1964 Declaration of Helsinki and its later amendments. Informed consent was obtained from all individual adult participants included in the study.

Conflicts of Interest The authors declare they have no conflict of interest.

Open Access This article is licensed under a Creative Commons Attribution 4.0 International License, which permits use, sharing, adaptation, distribution and reproduction in any medium or format, as long as you give appropriate credit to the original author(s) and the source, provide a link to the Creative Commons licence, and indicate if changes were made. The images or other third party material in this article are included in the article's Creative Commons licence, unless indicated otherwise in a credit line to the material. If material is not included in the article's Creative Commons licence and your intended use is not permitted by statutory regulation or exceeds the permitted use, you will need to obtain permission directly from the copyright holder. To view a copy of this licence, visit http://creativecommons.org/licenses/by/4.0/.

\section{References}

Agrawal, N., \& Wan, E. W. (2009). Regulating risk or risking regulation? Construal levels and depletion effects in the processing of health messages. Journal of Consumer Research, 36(3), 448-462. https://doi.org/10.1086/597331

Alberts, H. J. E., Martijn, C., Nievelstein, F., Jansen, A., \& De Vries, N. K. (2008). Distracting the Self: Shifting Attention Prevents Ego Depletion. Self and Identity, 7, 322-334. https://doi.org/10. 1080/15298860801987583

Bargh, J. A., Gollwitzer, P. M., Lee-Chai, A., Barndollar, K., \& Trötschel, R. (2001). The automated will: Nonconscious activation and pursuit of behavioral goals. Journal of Personality and Social Psychology, 81(6), 1014-1027. https://doi.org/10.1037// O022-3514.81.6.1014

Baumeister, R. F. (2002). Ego depletion and self-control failure: An energy model of the self's executive function. Self and Identity, 1(2), 129-136. https://doi.org/10.1080/152988602317319302

Baumeister, R. F. (2019). Self-control, ego depletion, and social psychology's replication crisis. In A. Mele (Ed.), Surrounding self-control. Oxford University Press. https://doi.org/10.31234/osf.io/uf3cn

Baumeister, R. F., Bratslavsky, E., Muraven, M., \& Tice, D. M. (1998). Ego depletion: Is the active self a limited resource? Journal of Personality and Social Psychology, 74(5), 1252-1265. https://doi. org/10.1037/0022-3514.74.5.1252

Baumeister, R. F., Gailliot, M., DeWall, C. N., \& Oaten, M. (2006). Self regulation and personality: How interventions increase regulatory success, and how depletion moderates the effects of traits on behavior. Journal of Personality, 74(6), 1773-1802. https:// doi.org/10.1111/j.1467-6494.2006.00428.x

Baumeister, R. F., Heatherton, T. F., \& Tice, D. M. (1994). Losing control: How and why people fail at self-regulation. Academic Press.

Baumeister, R. F., \& Vohs, K. D. (2016). Misguided effort with elusive implications. Perspectives on Psychological Science, 11, 574-575. https://doi.org/10.1177/1745691616652878

Bertrams, A., \& Schmeichel, B. J. (2014). Improving self-control by practicing logical reasoning. Self and Identity, 13(4), 419-431. https://doi.org/10.1080/15298868.2013.836562

Bertrams, A., Unger, A., \& Dickhäuser, O. (2011). Momentan verfügbare Selbstkontrollkraft - Vorstellung eines Messinstruments 
und erste Befunde aus pädagogisch-psychologischen Kontexten[Currently available self-control strength - Presentation of a measurement tool and first findings from pedagogical and psychological contextes]. Zeitschrift Für Pädagogische Psychologie, 25(3), 185-196. https://doi.org/10.1024/1010-0652/ a000042

Bruyneel, S.D., \& Dewitte S. (2006) Exerting self-control induces a narrow mindset. KUL Working Paper No. MO 0603. https://doi. org/10.2139/ssrn.944408

Bruyneel, S. D., \& Dewitte, S. (2012). Engaging in self-regulation results in low-level construals. European Journal of Social Psychology, 42(6), 763-776. https://doi.org/10.1002/ejsp.1896

Bruyneel, S. D., Dewitte, S., Vohs, K. D., \& Warlop, L. (2005). Repeated choosing increases susceptibility to affective product features. International Journal of Research in Marketing, 23(2), 215-225. https://doi.org/10.1016/j.ijresmar.2005.12.002

Calderon, S., Mac Giolla, M., Ask, K., \& Granhag, P. A. (2020). Subjective likelihood and the construal level of future events: A replication sudy of Wakslak, Trope, Liberman, and Alony (2006). Journal of Personality and Social Psychology, 119(5), 27-37. https://doi.org/10.1037/pspa0000214

Carter, E. C., Kofler, L. M., Forster, D. E., \& McCullough, M. E. (2015). A series of meta-analytic tests of the depletion effect: Self-control does not seem to rely on a limited resource. Journal of Experimental Psychology: General, 144(4), 796-815. https:// doi.org/10.1037/xge0000083

Carter, E. C., \& McCullough, M. E. (2014). Publication bias and the limited strength model of self-control: Has the evidence for ego depletion been overestimated? Frontiers in Psychology, 5, 823. https://doi.org/10.3389/fpsyg.2014.00823

Dang, J., Barker, P., Baumert, A., Bentvelzen, M., Berkman, E., Buchholz, N., \& Zinkernagel, A. (2021). A multi-lab replication of the ego depletion effect. Social Psychology and Personality Science, 12(1), 14-24. https://doi.org/10.1177/1948550619887702

Dang, J. H., Liu, Y., Liu, X., \& Mao, L. (2017). The ego could be depleted, providing initial exertion is depleting. Social Psychology, 48, 242-245. https://doi.org/10.1027/1864-9335/a000308

European Association of Social Psychology (2021). Call for labs for construal level theory replication project - Construal Level Int. Multilab Replication (CLIMR). Retrieved from https://www.easp. eu/news/itm/call_for_labs_for_construal_leve-1110.html

Fiedler, K., Jung, J., Wänke, M., \& Alexopoulos, T. (2012). On the relations between distinct aspects of psychological distance: An ecological basis of construal-level theory. Journal of Experimental Social Psychology, 48(5), 1014-1021. https://doi.org/10.1016/j. jesp.2012.03.013

Freitas, A. L., Salovey, P., \& Liberman, N. (2001). Abstract and concrete self-evaluative goals. Journal of Personality and Social Psychology, 80(3), 410-412. https://doi.org/10.1037/0022-3514. 80.3.410

Freitas, A. L., Gollwitzer, P. M., \& Trope, Y. (2004). The influence of abstract and concrete mindsets on anticipating and guiding others' self-regulatory efforts. Journal of Experimental Social Psychology, 40(6), 739-752. https://doi.org/10.1016/j.jesp.2004.04.003

Friese, M., Loschelder, D. D., Gieseler, K., Frankenbach, J., \& Inzlicht, M. (2019). Is ego depletion real? An analysis of arguments. Personality and Social Psychology Review, 23, 107-131. https:// doi.org/10.1177/1088868318762183

Fujita, K. (2008). Seeing the forest beyond the trees: A construal-level approach to self-control. Social and Personality Psychology Compass, 2(3), 1475-1496. https://doi.org/10.1111/j.1751-9004.2008. 00118.x

Fujita, K., \& Carnevale, J. J. (2012). Transcending temptation through abstraction: The role of construal level in self-control. Current Directions in Psychological Science, 21(4), 248-252. https://doi. org/10.1177/0963721412449169
Fujita, K., \& Han, H. A. (2009). Moving beyond deliberative control of impulses: The effect of construal levels on evaluative associations in self-control conflicts. Psychological Science, 20(7), 799-804. https://doi.org/10.1111/j.1467-9280.2009.02372.x

Fujita, K., Henderson, M. D., Eng, J., Trope, Y., \& Liberman, N. (2006a). Spatial distance and mental construal of social events. Psychological Science, 17(4), 278-282. https://doi.org/10.1111/j. 1467-9280,2006.01698.x

Fujita, K., \& Roberts, J. C. (2010). Promoting prospective self-control through abstraction. Journal of Experimental Social Psychology, 46(6), 1049-1054. https://doi.org/10.1016/j.jesp.2010.05.013

Fujita, K., \& Sasota, J. A. (2011). The effects of construal levels on asymmetric temptation-goal cognitive associations. Social Cognition, 29(2), 125-146. https://doi.org/10.1521/soco.2011.29.2.125

Fujita, K., Trope, Y., Liberman, N., \& Levin-Sagi, M. (2006b). Construal levels and self-control. Journal of Personality and Social Psychology, 90(3), 351-367. https://doi.org/10.1037/0022-3514. 90.3.351

Garrison, K. E., Finley, A. J., \& Schmeichel, B. J. (2019). Ego depletion reduces attention control: Evidence from two high-powered preregistered experiments. Personality and Social Psychology Bulletin, 45(5), 728-739. https://doi.org/10.1177/0146167218 796473

Gollwitzer, P. M. (1999). Implementation intentions: Strong effects of simple plans. American Psychologist, 54(7), 493-503. https://doi. org/10.1037/0003-066X.54.7.493

Gollwitzer, P. M. (2012). Mindset theory of action phases. Mindset theory of action phases. In P. A. M. Van Lange, A. W. Kruglanski, \& E. T. Higgins (Eds.), Handbook of theories of social psychology (pp. 526-545). Sage.

Gollwitzer, P., \& Bayer, U. (1999). Deliberative versus implemental mindsets in the control of action. In S. Chaiken \& Y. Trope (Eds.), Dual-process theories in social psychology (pp. 403-422). Guilford Press.

Gollwitzer, P. M., \& Sheeran, P. (2006). Implementation intentions and goal achievement: A meta-analysis of effects and processes. Advances in Experimental Social Psychology, 38, 69-119. https:// doi.org/10.1016/S0065-2601(06)38002-1

Hagger, M. S., Chatzisarantis, N. L., Alberts, H., Anggono, C. O., Batailler, C., Birt, A. R., \& Calvillo, D. P. (2016). A multilab preregistered replication of the ego-depletion effect. Perspectives on Psychological Science, 11, 546-573. https://doi.org/10.1177/ 1745691616652873

Hansen, J., \& Trope, Y. (2013). When time flies: How abstract and concrete mental construal affect the perception of time. Journal of Experimental Psychology: General, 142(2), 336-347. https:// doi.org/10.1037/a0029283

Hansen, J., \& Wänke, M. (2010). Truth from language and truth from fit: The impact of linguistic concreteness and level of construal on subjective truth. Personality and Social Psychology Bulletin, 36(11), 1576-1588. https://doi.org/10.1177/ 0146167210386238

Higgins, E. T. (1998). Promotion and prevention: Regulatory focus as a motivational principle. Advances in Experimental Social Psychology, 30, 1-46. https://doi.org/10.1016/S0065-2601(08)60381-0

Inzlicht, M., \& Schmeichel, B. J. (2012). What is ego depletion? Toward a mechanistic revision of the resource model of self control. Perspectives on Psychological Science, 7, 450-463. https:// doi.org/10.1177/1745691612454134

Inzlicht, M., \& Friese, M. (2019). The past, present, and future of ego depletion. Social Psychology, 50(5-6), 370-378. https://doi.org/ 10.1027/1864-9335/a00039

Keller, L., Bieleke, M., \& Gollwitzer, P. M. (2019). Mindset theory of action phases and if-then planning. In K. Sassenberg \& M. L. W. Vliek (Eds.), Social psychology in action (pp. 23-37). Springer. https://doi.org/10.1007/978-3-030-13788-5_2 
Leary, M. R., Adams, C. E., \& Tate, E. B. (2006). Hypo-egoic selfregulation: Exercising self-control by diminishing the influence of the self. Journal of Personality, 74, 1803-1831. https://doi.org/ 10.1111/j.1467-6494.2006.00429.x

Lee, N., Chatzisarantis, N., \& Hagger, M. S. (2016). Adequacy of the sequential-task paradigm in evoking ego-depletion and how to improve detection of ego-depleting phenomena. Frontiers in Psychology, 7, 136. https://doi.org/10.3389/fpsyg.2016.00136

Liberman, N., Sagristano, M. D., \& Trope, Y. (2002). The effect of temporal distance on level of mental construal. Journal of Experimental Social Psychology, 38(6), 523-534. https://doi.org/10. 1016/S0022-1031(02)00535-8

Liberman, N., \& Trope, Y. (1998). The role of feasibility and desirability considerations in near and distant future decisions: A test of temporal construal theory. Journal of Personality and Social Psychology, 75(1), 5-18. https://doi.org/10.1037/0022-3514.75.1.5

Liberman, N., \& Trope, Y. (2008). The psychology of transcending the here and now. Science, 322(5905), 1201-1205. https://doi.org/10. 1126/science. 1161958

Lurquin, J. H., Michaelson, L. E., Barker, J. E., Gustavson, D. E., von Bastian, C. C., Carruth, N. P., \& Miyake, A. (2016). No evidence of the ego-depletion effect across task characteristics and individual differences: A pre-registered study. PLoS One, 11, e0147770. https://doi.org/10.1371/journal.pone.0147770

Lurquin, J.H., \& Miyake, A. (2017). Challenges to ego-depletion research go beyond the replication crisis: A need for tackling the conceptual crisis. Frontiers in Psychology, 8(568). https://doi.org/ 10.3389/fpsyg.2017.00568

Metcalfe, J., \& Mischel, W. (1999). A hot/coolsystem analysis of delay of gratification: Dynamics of willpower. Psychological Review, 106, 3-19. https://doi.org/10.1037/0033-295X.106.1.3

Monsell, S. (2003). Task switching. Trends in Cognitive Sciences, 7(3), 134-140. https://doi.org/10.1016/S1364-6613(03)00028-7

Muraven, M., \& Baumeister, R. F. (2000). Self-regulation and depletion of limited resources: Does self-control resemble a muscle? Psychological Bulletin, 126(2), 247-259. https://doi.org/10.1037// 0033-2909.126.2.247

Muraven, M., Shmueli, D., \& Burkley, E. (2006). Conserving selfcontrol strength. Journal of Personality and Social Psychology, 91(3), 524-537. https://doi.org/10.1037/0022-3514.91.3.524

Nan, X. (2007). Social distance, framing, and judgment: A construal level perspective. Human Communication Research, 33(4), 489514. https://doi.org/10.1111/j.1468-2958.2007.00309.x

Nguyen, T., Carnevale, J. J., Scholer, A. A., Miele, D. B., \& Fujita, K. (2019). Metamotivational knowledge of the role of high-level and low-level construal in goal-relevant task performance. Journal of Personality and Social Psychology, 117(5), 876-899. https://doi. org/10.1037/pspa0000166

Rogers, R. D., \& Monsell, S. (1995). Costs of a predictable switch between simple cognitive tasks. Journal of Experimental Psychology-General, 124(2), 207-31. https://doi.org/10.1037/0096-3445.124.2.207

Schmeichel, B. J., \& Vohs, K. D. (2009). Self-affirmation and selfcontrol: Affirming core values counteracts ego depletion. Journal of Personality and Social Psychology, 96(4), 770-782. https://doi. org/10.1037/a0014635

Schmeichel, B. J., Vohs, K. D., \& Duke, C. S. (2011). Self-control at high and low levels of mental construal. Social Psychological and Personality Science, 2(2), 182-189. https://doi.org/10.1177/ 1948550610385955

Shenhav, A., Musslick, S., Lieder, F., Kool, W., Griffiths, T. L., Cohen, J. D., \& Botvinick, M. M. (2017). Toward a rational and mechanistic account of mental effort. Annual Review of Neuroscience, 40, 99-124. https://doi.org/10.1146/annurev-neuro-072116-031526

Siddiqui, R. A., May, F., \& Monga, A. (2014). Reversals of task duration estimates: Thinking how rather than why shrinks duration estimates for simple tasks, but elongates estimates for complex tasks. Journal of Experimental Social Psychology, 50, 184-189. https://doi.org/10.1016/j.jesp.2013.10.002

Soderberg, C. K., Callahan, S. P., Kochersberger, A. O., Amit, E., \& Ledgerwood, A. (2015). The effects of psychological distance on abstraction: Two meta-analyses. Psychological Bulletin, 141(3), 525-548. https://doi.org/10.1037/bul0000005

Stephan, E., Liberman, N., \& Trope, Y. (2010). Politeness and psychological distance: A construal level perspective. Journal of Personality and Social Psychology, 98(2), 268-280. https://doi. org/10.1037/a0016960

Stephan, E., Liberman, N., \& Trope, Y. (2011). The effects of time perspective and level of construal on social distance. Journal of Experimental Social Psychology, 47(2), 397-402. https://doi.org/ 10.1016/j.jesp.2010.11.001

Trope, Y., \& Liberman, N. (2000). Temporal construal and timedependent changes in preference. Journal of Personality and Social Psychology, 79(6), 876-889. https://doi.org/10.1037// 0022-3514.79.6.876

Trope, Y., \& Liberman, N. (2010). Construal-level theory of psychological distance. Psychological Review, 117(2), 440-463. https:// doi.org/10.1037/a0018963

Ülkümen, G., \& Cheema, A. (2011). Framing goals to influence personal savings: The role of specificity and construal Level. Journal of Marketing Research, 48(6), 958-969. https://doi.org/10.1509/ jmr.09.0516

Uziel, L., \& Baumeister, R. F. (2017). The self-control irony: Desire for self-control limits exertion of self-control in demanding settings. Personality and Social Psychology Bulletin, 43(5), 693-705. https://doi.org/10.1177/0146167217695555

Vadillo, M. A. (2019). Ego depletion may disappear by 2020. Social Psychology, 50(5-6), 282-291. https://doi.org/10.1027/18649335/a000375

Wakslak, C., \& Trope, Y. (2009). The effect of construal level on subjective probability estimates. Psychological Science, 20(1), 52-58. https://doi.org/10.1111/j.1467-9280.2008.02250.x

Wan, E. W., \& Agrawal, N. (2011). Carryover effects of self-control on decision making: A construal-level perspective. Journal of Consumer Research, 38(1), 199-214. https://doi.org/10.1086/658471

Webb, T. L., \& Sheeran, P. (2003). Can implementation intentions help to overcome ego-depletion? Journal of Experimental Social Psychology, 39, 279-286. https://doi.org/10.1016/S0022-1031(02) 00527-9

Wolff, W., Baumann, L., \& Englert, C. (2018). Self-reports from behind the scenes: Questionable research practices and rates of replication in ego depletion research. PLoS One, 13(6), e0199554. https://doi.org/10.1371/journal.pone.0199554

Xu, X., Demos, K. E., Leahey, T. M., Hart, C. N., Trautvetter, J., Coward, P., \& Wing, R. R. (2014). Failure to replicate depletion of self-control. PLoS One, 9, e109950. https://doi.org/10.1371/journ al.pone. 0109950

Yan, J., Hou, S., \& Unger, A. (2014). High construal level reduces overoptimistic performance prediction. Social Behavior and Personality, 42(8), 1303-1313. https://doi.org/10.2224/sbp.2014.42.8.1303

Yan, J., Zhang, N. N., \& Xu, D. X. (2018). Mindset switching increases the use of "want-based" over "should-based" behaviors. PLoS One, 13(4), 1-25. https://doi.org/10.1371/journal.pone.0196269

Žeželj, I. L., \& Jokić, B. R. (2014). Replication of experiments evaluating impact of psychological distance on moral judgment (Eyal, Liberman \& Trope, 2008; Gong \& Medin, 2012). Social Psychology, 45(3), 223231. https://doi.org/10.1027/1864-9335/ a000188

Publisher's note Springer Nature remains neutral with regard to jurisdictional claims in published maps and institutional affiliations. 